\title{
Djinnati Syndrome in Baluchestan: The Role of Traumatic and Abuse Experiences on Individual Vulnerability
}

\author{
Nasrin Hosseinbor ${ }^{1}$; Nour-Mohammad Bakhshani ${ }^{2,}$ \\ ${ }^{1}$ Department of Clinincal Psychology, Fars Sciences and Research Branch, Islamic Azad University, Shiraz, IR Iran \\ ${ }^{2}$ Children and Adolescents' Health Research Center, Department of Clinincal Psychology, Zahedan University of Medical Sciences, Zahedan, IR Iran \\ *Corresponding author: Nour Mohammad Bakhshani, Children and Adolescents' Health Research Center, Department of Clinincal Psychology, Zahedan University of Medical Sci- \\ ences, Zahedan, IR Iran. Tel: + 98-5433522636, Fax: +98-5433522636, E-mail: nmbs14@yahoo.com
}

Received: September 14, 2014; Revised: September 16, 2014; Accepted: September 16, 2014

Keywords: Stress Disorders, Traumatic; Child Abuse; Dissociative Disorders

Djinnati is a culture-bound syndrome in Baluchestan, Iran. Experts believe that dissociation theory is more suitable for providing a psychopathological description of this syndrome in this region. In addition, they highlight the need for investigating its pathology, particularly the role of factors such as traumatic and abuse experiences during childhood.

According to the 4th edition of the diagnostic and statistical manual of mental disorders (DSM-IV-TR) (1), "the essential feature of dissociative disorders is a disruption in the usually integrated functions of consciousness, memory, identity, or perception of the environment. The disturbance may be sudden or gradual, transient or chronic". According to DSM-IV-TR, dissociative disorders include: dissociative identity disorder, depersonalization disorder, dissociative amnesia, dissociative fugue and unspecified dissociative disorder. A dissociate disorder not otherwise specified (NOS) is a disorder that includes a dissociative symptom (i.e. disturbance in the usually integrated functions of consciousness, memory, identity or perception of the environment), that does not meet the criteria for any specific dissociative disorder.

In addition, according to DSM a dissociative state may be defined as a dissociative trance disorder that includes a possession or trance state. Dissociative trance disorder is a single or episodic disturbance in the state of consciousness, identity, or memory that are indigenous to particular locations and cultures. Dissociative trance involves narrowing of awareness of immediate surroundings or stereotyped behaviors or movements that are experienced as being beyond one's control. Possession trance involves replacement of the customary sense of personal identity or a new identity, attributed to the influence of a spirit, power, deity, or other person, and is associated with stereotyped "involuntary" movements or amnesia. It is probably the most prevalent dissociative disorder in Asia. The dissociative or trance disorder is not a normal part of a broadly accepted collective cultural or religious practice.

Many culture-related syndromes, such as amok, bebainan, latah, pibloktoq, ataque de nervios and possession, shin-byung, enchantment, lack of spirit, Zar and djinnati $(2,3)$, are considered as dissociative disorders. Culture-bound syndromes include a set of psychological phenomena that are of interest to psychologists and psychiatrists. The eclectic nature of this syndrome has made it difficult to have a precise definition. Thus, deciding on a specific definition has been controversial. According to DSM, the term culture-bound syndrome denotes a locality-specific pattern and repetition of an aberrant behavior and troubling experience that may or may not be linked to a particular DSM-IV diagnostic category. Many of these patterns are indigenously considered to be "illnesses", or at least afflictions that mostly have local names. Culturebound syndromes do not one-by-one match routine diagnostic system diseases. Most of these syndromes were initially reported as an issue specific to a certain culture or a relevant set, or geographically-related to the original culture (4).

The term "Djinnati" is a culture-bound syndrome, widely known by that name in Iranian and Pakistani Baluchestan $(3,5)$. Based on clinical observations, this syndrome was introduced by Bakhshani and Kianpoor in Baluchestan, Iran (6). A new study by Bakhshani et al. (3) on a rural population in Baluchestan showed total prevalence of $0.5 \%$ and $1.03 \%$ among the rural population and women of that population, respectively. Common symptoms of this disorder include disruption in consciousness, memory and stereotyped behaviors such as laughing, crying, speaking incomprehensibly, which are attributed to a new identity known as "Djinn". Attacks usually begin with pain, irritation and sometimes limb

Copyright (C) 2014,Zahedan University of Medical Sciences; Published by Kowsar. This is an open-access article distributed under the terms of the Creative Commons Attribution-NonCommercial 4.0 International License (http://creativecommons.org/licenses/by-nc/4.0/) which permits copy and redistribute the material just in noncommercial usages, provided the original work is properly cited. 
paralysis. In some groups, loss of speech and in some other cases, speaking in different languages and change in speaking rhythm and tone of voice have been reported. In addition, there was a partial and rarely complete amnesia during the attack. Some patients were far beyond their physical strength. In addition, lack of control and harming themselves and others, during the attack, have been reported; although, the injuries were not serious. Sometimes during the attack, The patients express some demands and the possessor (Djinn) requests for satisfying these demands. Attacks usually last from 30 minutes to two hours (3).

It seems that traumatic and abuse experiences have an essential role in the initiation and maintenance of dissociative disorders $(7,8)$. Results from Bakhshani et al. (3) study showed that $43 \%$ of the patients experienced their first attack after a traumatic accident (5). After the civil war of Mozambique, based on results of a study reported by Igreja et al. (9) on 941 subjects ( 255 males and 686 females), trauma and civil war resulted damages, which explain the high prevalence of this disorder.

Castillo (10), believes that biological and psychoanalytic perspectives are not capable of explaining spirit possession. Etiologically, he suggested that spirit possession, similar to multiple personality disorder (MPD), is a spontaneous trance reaction to severe and negative events in environment (particularly child abuse). On the other hand, Naring and Nijenhuis observed a significant correlation between traumatic events and possession experiences (11). In addition, Naring and Nijenhuis (11) considered dissociative identity disorder to be a consequence of childhood abuse or other traumatic events, thus support the post-trauma model. In this regard, a study by Pasquini et al.(12), showed a relationship between traumatic experience in childhood and development of dissociative disorders. Kaplan et al. (13) found that those with higher score in dissociative experience scale had been more sexually abused during their childhood. They have been reported to commit further suicide and aggressive behaviors (13).

In general, it can be concluded that traumatic experiences, specifically childhood maltreatment and abuse, are related to possession and dissociative experiences. Therefore, in future studies, it is required to investigate the type of cultural beliefs abuse and other environmental factors with the onset of clinical signs of Djinatti, and then develop and practice preventive and therapeutic approaches, based on the findings.

\section{Authors' Contributions}

The whole article has been written by Authors.

\section{References}

1. American Psychiatric Association . Diagnostic and Statistical Manual of Mental Disorders. USA: American Psychiatric Association; 2000.

2. Spiegel D, Loewenstein RJ, Lewis-Fernandez R, Sar V, Simeon D, Vermetten E, et al. Dissociative disorders in DSM-5. Depress Anxiety. 2011;28(9):824-52.

3. Bakhshani NM, Hosseinbore N, Kianpoor M. Djinnati syndrome: symptoms and prevalence in rural population of Baluchistan (southeast of Iran). Asian J Psychiatr. 2013;6(6):566-70.

4. Shiraev EB, Levy DA. Cross-Cultural Psychology Critical Thinking and Contemporary Applications. Allyn \& Bacon; 2010.

5. Kianpoor M, Rhoades Jr, George F. Djinnati, A Possession State in Baloochistan, Iran. J Trauma Pract. 2006;4(1-2):147-55.

6. Bakhshani NM, Kianpoor M. Djinnati: clinical symptoms and traditional treatment. 2nd Congress of Socio Cultural Psychiatry. Tehran, Iran. 1998.

7. van Duijl M, Nijenhuis E, Komproe IH, Gernaat HB, de Jong JT. Dissociative symptoms and reported trauma among patients with spirit possession and matched healthy controls in Uganda. Cult Med Psychiatry. 2010;34(2):380-400.

8. Bernier MJ, Hebert M, Collin-Vezina D. Dissociative symptoms over a year in a sample of sexually abused children.J Trauma Dissociation. 2013;14(4):455-72.

9. Igreja V, Dias-Lambranca B, Hershey DA, Racin L, Richters A, Reis R The epidemiology of spirit possession in the aftermath of mass political violence in Mozambique. Soc Sci Med. 2010;71(3):592-9.

10. Castillo RJ. Spirit possession in South Asia, dissociation or hysteria? Part 2: Case histories. Cult Med Psychiatry. 1994;18(2):141-62.

11. Naring G, Nijenhuis ERS. Relationships between self-reported potentially traumatizing events, psychoform and somatoform dissociation, and absorption, in two non-clinical populations. Aust N Z J Psychiatry. 2005;39(11-12):982-8.

12. Pasquini P, Liotti G, Mazzotti E, Fassone G, Picardi A. Risk factors in the early family life of patients suffering from dissociative disorders. Acta Psychiatr Scand. 2002;105(2):110-6.

13. Kaplan ML, Erensaft M, Sanderson WC, Wetzler S, Foote B, Asnis GM. Dissociative symptomatology and aggressive behavior. Compr Psychiatry. 1998;39(5):271-6. 